\title{
Os textos críticos sobre o filme 0 Som ao Redor, seus pressupostos estéticos e desdobramentos hermenêuticos ${ }^{1}$
}

\section{Rogério de Almeida ${ }^{2}$ Christian Hugo Pelegrini ${ }^{3}$}

Recibido: 2015-09-01

Enviado a pares: 2015-09-07
Aprobado por pares: 2016-01-13

Aceptado: 2016-01-20

DOI: 10.5294/pacla.2016.19.3.3

Para citar este artículo / to reference this article / para citar este artigo Almedia, R. y Pelegrini, C. H. (2016). Os textos críticos sobre o filme 0 Som ao Redor, seus pressupostos estéticos e desdobramentos hermenêuticos. Palabra Clave, 19(3), 721-745. DOI: 10.5294/pacla.2016.19.3.3

\section{Resumo}

Este artigo tem por objetivo empreender uma análise hermenêutica dos textos críticos veiculados nos principais jornais, revistas e sites sobre o filme O Som ao Redor, do cineasta Kleber Mendonça Filho. Foram selecionados 16 textos críticos, os quais forneceram subsídios para a observação, entre outros elementos, da recorrência de três pressupostos estéticos: o aspecto sociológico do filme, pelo qual é possível compreendê-lo como uma metáfora ou um discurso sobre o Brasil; a estética da mistura de gêneros, a partir, principalmente, dos recursos sonoros empregados no longa-metragem e, por fim, o caráter inovador, critério moderno que valoriza o potencial de novidade contido numa obra.

\section{Palavras-chave}

Cinema; recepção crítica; hermenêutica (Fonte: Tesauro da Unesco).

1 Este artigo é resultado de projeto de pesquisa financiado pela Fundação de Amparo à Pesquisa do Estado de São Paulo (FAPESP).

2 Universidade de São Paulo, Brasil. rogerioa@usp.br

3 Universidade Federal de Juiz de Fora, Brasil.christian.pelegrini@gmail.com 


\section{Los textos críticos acerca de la película o Som ao Redor, sus presupuestos estéticos y despliegues hermenéuticos}

\section{Resumen}

El artículo tiene como fin emprender un análisis hermenéutico de los textos críticos en circulación en los principales periódicos, revistas y sites acerca de la película $O$ Som ao Redor, del cineasta Kleber Mendonça Filho. Se seleccionaron 16 textos críticos, los que brindaron subsidios para la observación, entre otros elementos, de la recurrencia de tres presupuestos estéticos: el aspecto sociológico de la película, mediante el cual es posible comprenderla como una metáfora o un discurso sobre Brasil; la estética de la mezcla de géneros, desde, sobre todo, los recursos sonoros utilizados en el largometraje, y, por fin, el carácter innovador, criterio moderno que valora el potencial de novedoso contenido en una obra.

\section{Palabras clave}

Cine; recepción crítica; hermenéutica (Fuente: Tesauro de la Unesco). 


\section{Critical Reviews of the Film 0 Som ao Redor, its Aesthetic Proposals and Hermeneutic Deployment}

\section{Abstract}

The article undertakes a hermeneutical analysis of a series of critical reviews appearing in major newspapers, magazines and media sites on $O$ Som ao Redor, by the filmmaker Kleber Mendonça Filho. Sixteen reviews were selected. They provide support for observing, among other elements, the recurrence of three aesthetic proposals: the sociological aspect, whereby it is possible to understand the film as a metaphor or a discourse on Brazil; the aesthetics of the mixture of genres, particularly the sound resources used in this feature film, and, lastly, its innovative nature or modern criterion that values the potential of novel content in a work of art.

\section{Keywords}

Cinema; critical reception; hermeneutics (Source: Unesco Thesaurus). 


\section{Introdução}

Presume-se que o papel da crítica de cinema veiculada nos principais jornais do mundo e, desde a internet, difundida por sites especializados, tenha por objetivo apresentar, comentar, avaliar os filmes, não como uma devolutiva para o cineasta, mas como orientação para o público. Diferente da pesquisa acadêmica, que resulta em livros e artigos, e cuja análise de determinado filme ou conjunto de filmes obedece a regras e métodos próprios da linguagem e prática científicas sem urgência temporal, a crítica cinematográfica dos jornais e sites é predominantemente contemporânea ao lançamento do filme. Respeita, salvo raras exceções, a não revelação do seu desfecho e a apresentação de elementos parciais do enredo já que muitos leitores não assistiram ao filme e apostam que a crítica poderá orientá-los quanto a isso. Outras características da crítica de difusão são sua brevidade de extensão e a facultativa menção a conceitos teóricos e estéticos.

Em verbete dedicado à crítica, Jacques Aumont e Michel Marie (2003, p. 9) designam sua dupla função: informação e avaliação. Para os autores, o "juízo crítico apoia-se em valores estéticos e em certas noções gerais" e não cabe o papel da "análise, cujo objetivo é esclarecer o funcionamento e propor uma interpretação da obra artística” (Aumont e Marie, 2003, p. 9). Espera-se da crítica, portanto, um juízo, uma avaliação, a atribuição de um valor estético, mas não só estético, a partir de certa concepção, raríssimas vezes expressa, do que seja a arte cinematográfica.

Poderíamos, a partir dessa definição, indagar sobre qual(is) concepção(ões) estética(s) nortearia(m) o trabalho do crítico de cinema. Uma vez que essa concepção estética não é explicitada, somos forçados a presumi-la como um pressuposto que orienta a leitura do crítico.

Não obstante, como chegar a esses pressupostos estéticos? Ou, indagado de outra forma, como inferir o diálogo que os críticos travam com as obras cinematográficas quando se dedicam a escrever críticas de difusão? Qual o horizonte de validação de seus julgamentos? Como avaliar os valores que atribuem ou deixam de atribuir aos filmes resenhados? 
Tais questões buscam interpretar esse movimento valorativo da crítica, compreender como os críticos exercitam seu olhar. Portanto, são questões de ordem hermenêutica, visam à compreensão da compreensão ou aos modos de interpretar, ler, avaliar um filme. Para atingir esse objetivo, recorreremos teoricamente às contribuições de Paul Ricoeur (2008) sobre os estudos da hermenêutica e de Tzvetan Todorov (2003) acerca dos modos de leitura. Como metodologia, analisaremos 16 textos críticos veiculados por ocasião do lançamento comercial (início de 2013) do filme O Som ao Redor ${ }^{4}$, do cineasta Kleber Mendonça Filho. Algumas são anteriores à sua estreia, fruto de assistência em festivais, e as demais posteriores e retomam o filme como fenômeno, se não de público, ao menos de repercussão crítica. Esta é uma das razões pela escolha do longa-metragem, aliado ao fato de quase unanimemente ser considerado um dos melhores filmes surgidos nos últimos anos no Brasil ou desde a retomada, conceito frequentemente utilizado para a produção cinematográfica pós-era Collor ${ }^{5}$.

\section{A proposição de mundo diante do texto}

Em seus estudos sobre hermenêutica, Paul Ricoeur (2008) visa ultrapassar a antinomia que Gadamer (citado por Ricoeur, 2008, p. 21) apontou entre a prática de uma atitude metodológica, com a qual se perde a densidade ontológica da realidade estudada, e a prática da atitude de verdade, com a qual se renuncia à objetividade das ciências humanas. Ou estamos do lado do método, o que valida as ciências humanas e possibilita uma objetivação do objeto em estudo, ou estamos em relação estrita com a realidade vivida, com sua verdade, com o sentido emanado da pertença. Essa antinomia faz com que não haja, para Gadamer, alternativa entre o distanciamento alienante e a pertença (citado por Ricoeur, 2008, p. 24).

Paul Ricoeur busca superar essa antinomia conduzindo a problemática para outro campo, o do texto. Para Ricoeur, o texto é "muito mais que um caso particular de comunicação inter-humana: é o paradigma do distanciamento na comunicação" (2008, p. 52). O texto se apresenta como discurso;

\footnotetext{
O Som ao redor. Direção de Kleber Mendonça Filho. Brasil: 2012 (131 min), son., color.

5 Fernando Collor de Mello, presidente do Brasil entre 1990 e 1992, extinguiu a Embrafilme, responsável por fomentar a produção e a distribuição de filmes brasileiros. Sua extinção fez com que a produção cinematográfica no país paralisasse.
} 
o discurso se efetua como obra e a obra projeta, cria um mundo, "o mundo da obra”, que, para Ricoeur (2008, p. 53), é a grande questão hermenêutica: "o deslocamento do problema do texto em direção ao do mundo que ele abre".

Num primeiro passo argumentativo, Ricoeur aponta que o discurso se caracteriza pela dialética entre o evento e a significação. Evento porque o discurso se realiza temporalmente e no presente, enquanto o sistema da língua é virtual e fora do tempo. Assim, o evento remete ao seu locutor (instância autorreferencial do discurso): "o evento consiste no fato de alguém falar, de alguém se exprimir tomando a palavra” (Ricoeur, 2008, p. 54). Outra característica é que o discurso, conquanto perfaça um mundo em si, refere-se também a um mundo que pretende descrever, exprimir ou representar. Mas o discurso possui, além do mundo que expressa, o outro, outra pessoa, um interlocutor: "o evento é o fenômeno temporal da troca, o estabelecimento do diálogo” (Ricoeur, 2008, p. 55).

Contudo, o evento do discurso não se encerra em si, senão que é ultrapassado pela significação. $\mathrm{O}$ evento é fugidio, a significação é o que permanece. Esta se desdobra entre o que efetivamente é dito (ato locucionário ou proposicional), a convenção do que se diz (ato ilocucionário) — sua força: se é uma informação, uma ordem, um desejo- e, finalmente, o ato que não se realiza na linguagem, mas pela linguagem (ato pelocucionário), ou seja, os efeitos do discurso, os resultados provocados por ele. Segundo Ricoeur (2008, p. 57), a significação do ato de discurso não se limita ao correlato da frase (ato proposicional), mas engloba a força ilocucionária e a ação perlocucionária, "na medida em que esses três aspectos do ato de discurso são codificados e regulados segundo paradigmas”.

É, portanto, da tensão entre esses dois polos do discurso, o do evento e o da significação, que o discurso se produz como obra. Nesse sentido, o que caracteriza a obra? "Composição, pertença a um gênero, estilo individual” (Ricoeur, 2008, p. 58), ou seja, uma sequência mais longa que uma frase e que suscita um problema de compreensão (composição); uma forma de codificação do discurso em relato, poema, ensaio (gênero literário), e, finalmente, a configuração única que caracteriza o estilo de uma obra. 
Nessa perspectiva, vale salientar a discussão em torno do aspecto autoral no cinema como possibilidade de demarcação do estilo de determinados realizadores, o que validaria o cinema como obra de arte já que possui discurso, codifica-se como gênero e distingue-se pelo estilo de seus realizadores.

Para Ricoeur, uma obra, por meio da efetivação de seu discurso, propõe um mundo: "o que deve ser interpretado, num texto, é uma proposição de mundo, de um mundo tal como posso habitá-lo para nele projetar um de meus possíveis mais próprios. É o que chamo de o mundo do texto, o mundo próprio a este texto único" (Ricoeur, 2008, p. 66).

Sua ideia repousa, portanto, na negação de que a interpretação de um texto deva buscar as intenções ocultas do autor. Não devemos buscar o que está dissimulado por detrás do texto, pois "interpretar é explicitar o tipo de ser-no-mundo manifestado diante do texto” (Ricoeur, 2008, p. 65). Quem está diante do texto é o leitor, de modo que é no diálogo do interpretante com a obra que o sentido emerge.

Contudo, o final do percurso hermenêutico não está na interpretação da proposição de mundo de uma obra, mas no fato de essa interpretação se constituir como uma mediação pela qual compreendemos a nós mesmos:

Aquilo de que finalmente me aproprio é uma proposição de mundo.
Esta proposição não se encontra atrás do texto, como uma espécie
de intenção oculta, mas diante dele, como aquilo que a obra des-
venda, descobre, revela. Por conseguinte, compreender é compre-
ender-se diante do texto. Não se trata de impor ao texto sua própria
capacidade finita de compreender, mas de expor-se ao texto e re-
ceber dele um si mais amplo, que seria a proposição de existência
respondendo, da maneira mais apropriada possível, à proposição de
mundo (Ricoeur, 2008, p. 68).

A compreensão de uma obra é também autocompreensão, compreensão de si diante da obra. Por essa mesma razão, a incompreensão de um discurso não isenta o interlocutor já que é coautor dos sentidos produzidos. Assim, a despeito de toda objetividade que possa ser buscada ou de todo método que possa ser empregado, a interpretação depende da experiência subjetiva. 
[...] precisamos dar um passo à frente: assim como o mundo do texto só é real na medida em que é fictício, da mesma forma devemos dizer que a subjetividade do leitor só advém a ela mesma na medida em que é colocada em suspenso, irrealizada, potencializada, da mesma forma que o mundo manifestado pelo texto. Em outras palavras, se a ficção é uma dimensão fundamental da referência do texto, não possui menos uma dimensão fundamental da subjetividade do leitor. Só me encontro, como leitor, perdendo-me. A leitura me introduz nas variações imagináveis do ego (Ricoeur, 2008, p. 68).

Do trecho, algumas considerações importantes a fixar: primeiro, não há oposição entre ficção e realidade. A obra concretiza-se como uma mediação do real por meio da ficção. A obra não apreende o real. A imagem que vemos num filme não é o real, mas uma imagem desse real, incapaz de apreendê-lo, ainda que possa indicá-lo com grande propriedade. Assim, um texto literário ou uma narrativa fílmica relaciona-se com o real por meio da ficção, isto é, o real não subjaz como base, mas é construído subjetivamente. No vocabulário de Ricoeur, uma obra propõe um mundo fictício como mundo possível tornando o próprio mundo concreto como uma possibilidade discursiva entre outras.

A segunda consideração é que a subjetividade também é ficção, ou seja, é construída por meio de discursos. O contato com as obras nos auxilia na construção do eu. Há, portanto, no contato com a obra, não apenas uma relação de distanciamento entre aquele que elaborou seu discurso e este que agora o interpreta, mas também "um momento de distanciamento até na relação de si a si” (Ricoeur, 2008, p. 69), por meio do qual questiono a narração que faço de mim. É por isso que a compreensão da obra conduz à compreensão de si diante da obra, pois respondemos subjetivamente às intimações do mundo proposto por essa obra, numa trajetividade recursiva (Durand, 1997). Um exemplo: se releio um livro ou revejo um filme depois de um longo tempo, observo que minha interpretação, minha compreensão da obra mudou e, possivelmente, sou levado a observar o que em mim mudou confrontando os dois momentos da fruição.

Por fim, a terceira consideração é a dimensão formativa ou educativa do processo de diálogo, de interpretação e compreensão de uma obra e do mundo por ela proposto. Por meio das variações imagináveis do eu e do mundo 
que a leitura de uma obra suscita, somos levados a desestabilizar, a problematizar determinados discursos. No mínimo, enriquece-se o processo de compreensão da realidade — ou a compreensão do fato de que a realidade é construída numa tensão de discursos- Nesse sentido, a mediação ou o distanciamento que as obras de arte operam, principalmente as que se valem da estrutura narrativa, implicam um processo formativo, pois contribuem para que a pessoa se situe no mundo, o habite, transite por ele, seja na dimensão das convenções sociais, afetivas, seja no trato com o desejo, o instinto etc. (Ferreira-Santos e Almeida, 2012).

\section{A proposição crítica sobre 0 Som ao Redor}

De acordo com a hermenêutica de Paul Ricoeur, compreendemos que os discursos críticos sobre $O$ Som ao Redor se constituiriam, de um lado, pela busca da proposição de mundo presente no filme e, de outro, na compreensão de si diante do filme, ou seja, do próprio crítico, quando considerado individualmente, ou da própria crítica, quando considerada em conjunto. A crítica revelaria, então, o sentido do filme, mas também se revelaria na explicitação desse sentido mostrando quais são seus pressupostos subjetivos de leitura. Em outras palavras, a crítica não está imune à sua própria proposição de mundo quando se propõe perscrutar a proposição de mundo de um dado filme.

Procedendo à leitura das críticas, podemos reconhecer três pontos argumentativos recorrentes e ilustrativos do olhar crítico: o aspecto sociológico do filme, a estética da mistura de gêneros e o caráter inovador da obra.

\section{O filme como tese sociológica e histórica}

Quanto ao primeiro aspecto, O Som ao Redor é caracterizado como um filme que defende uma tese, que expõe o momento atual como resultado de um processo histórico continuado, que apresenta uma radiografia do Brasil pós-Lula ${ }^{6}$, o instantâneo do medo e da paranoia das classes abastadas, até mesmo como uma retomada política que reatualiza a luta de classes. Uni-

6 Luiz Inácio Lula da Silva, presidente do Brasil entre 2003 e 2011, foi responsável por políticas de distribuição de renda que permitiram a ascensão social da classes mais baixas e seu ingresso na sociedade de consumo, o que incomodou parte da elite social que se viu obrigada a conviver com esse grupo em shoppings centers, aeroportos etc. 
das essas constatações, podemos dizer que esse primeiro aspecto abordado pela crítica se filia a uma tradição de buscar nas obras nacionais, tanto da literatura quanto do cinema, um retrato do país. Não retomaremos aqui a longa discussão que remonta ao final do século retrasado, quando Machado de Assis foi acusado de não flagrar a cor local em sua literatura. Evidentemente, em tempos de mundialização da economia e globalização da cultura de massas, a dicotomia particular-universal ganhou outras conotações, mas ainda perdura certo interesse da crítica em ler as narrativas como retratos do país, como ocorreu com Central do Brasil (1998), Cidade de Deus (2002) e Tropa de Elite 1 e $2(2007,2010)$. Cada um ao seu modo, são filmes cuja recepção potencializou o caráter nacional de seu discurso. Um filme como Trabalhar Cansa (2011), que o próprio Kleber Mendonça Filho considerou "irmão" do seu $O$ Som ao Redor, teve repercussão bem menor, talvez pelo tema — as relações de trabalho e capital — não ter a cor local suficiente para o retrato buscado pela crítica.

Dessa forma, o retrato do Brasil presumivelmente pretendido pelo filme é exposto de maneira recorrente. Para Ricardo Calil (Folha de S. Paulo),

São necessários apenas cinco minutos para entender que, em seu primeiro longa de ficção, o cineasta Kleber Mendonça Filho quer matar a cobra e mostrar o pau.

Ao longo das duas horas seguintes, ele irá demonstrar que aquele momento de lazer entre muros - que denota tanto a divisão de classes quanto 0 medo da violência do Brasil do século 21- descende da separação entre casa grande e senzala e da lógica latifundiária dos engenhos do século 19.

Mas não espere uma tese acadêmica, didática e explanativa. "0 Som ao Redor" é um sofisticado quebra-cabeças cinematográfico (Calil, 2013).

Curioso como o crítico caracteriza a tese acadêmica e o peso que dá às palavras didática e explanativa, ao opô-las a sofisticado quebra-cabeças cinematográfico, o que conferiria certa supremacia ao diretor, que soube "matar a cobra e mostrar o pau" 7 .

7 Expressão popular que significa "provar o que se diz". 
Paulo Camargo (Gazeta do Povo) também reconhece o caráter de tese do filme, que "discute, sem recorrer ao didatismo ou a discursos ideológicos simplificadores, temas diversos, porém entrelaçados, como o conflito entre classes sociais, violência urbana, o poder paralelo das milícias e a especulação imobiliária nos grandes centros" (Camargo, 2013, १5). Conclui-se que, por discutir tais temas, o filme "é uma obra obrigatória para quem pretende compreender, em toda a sua complexidade, a sociedade brasileira contemporânea" (Camargo, 2013, |2).

Consuelo Lins ( $O$ Globo) destaca que "Poucas vezes a tensão social urbana no Brasil foi filmada com tamanha crueza, perspicácia e humor" (Lins, 2013, ी1) e chama atenção para o "realismo" do filme já no título de sua crítica: "Tensão social como ela é" (Lins, 2013).

\title{
Maurício Puls (Folha de S. Paulo) realça:
}

\begin{abstract}
Após tantos prêmios, não resta dúvida de que "O Som ao Redor" é o filme brasileiro mais significativo desde "Cidade de Deus" (2002). Nenhuma outra obra dos últimos anos produziu retrato tão abrangente da sociedade nacional, que de certo modo condensa a trajetória do país no período republicano (Puls, 2013, П1).
\end{abstract}

Para Celso Sabadin (Revista de Cinema), o filme "investiga um recorte do abismo social e econômico brasileiro visto sob o prisma de um bairro de classes média e alta de Recife" (Sabadin, 2013, १3). Depois de constatar que o filme retrata "a surda guerra civil que se vive há gerações no Brasil" (Sabadin, 2013, 凤3), o crítico arremata com um juízo histórico e historicista, menos voltado ao filme que a uma pretensa História do Brasil: "Prevalece a sensação do triste aprisionamento de todos aqueles personagens, cada qual deles refém de processos seculares da nossa história que, com o passar do tempo, se tornam mais agudos e mais insustentáveis" (Sabadin, 2013, १6).

A mesma constatação foi feita por Luiz Zanin (O Estado de S. Paulo), ao apontar que o filme

[...] liga duas vertentes da cultura pernambucana específica. Por um lado essa, urbana, da cidade temerosa e semidestruída pela especulação 
imobiliária sem freio; por outro, a origem senhorial das fortunas originadas nos engenhos, antigas como as capitanias hereditárias, e que agora se reciclam nas cidades. Do engenho de cana ao arranhacéu em Boa Viagem - eis o trânsito do capital em algumas gerações (Zanin, 2013, ๆ4).

Para Maria do Rosário Caetano (Brasil de Fato), o filme é "significativo" e "bom" por abordar "temas essenciais à compreensão de nosso tempo (a luta de classes, a especulação imobiliária, a violência urbana e rural, o racismo velado à brasileira, o consumismo desenfreado)" (Caetano, M. do R., 2013, П4).

O diagnóstico de Cesar Zamberlan (Revista Interlúdio) não é muito diferente:

Mas essas relações de poder, relações históricas, trabalhadas pelo filme sem juízo de valor, sem maniqueísmos, dão conta tanto da cordialidade, no sentido tratado por Sérgio Buarque de Holanda, como da eternização de certas relações de poder e de trabalho, ainda que tais relações sejam datadas do período colonial, caso dos senhores de engenho, mas que só agora e de certa forma começam a mudar, mesmo que lentamente (Zamberlan, 2013, १8).

O componente novo trazido por Zamberlan está na leitura política, uma vez que o crítico acredita que $O$ Som ao Redor "é um dos poucos, pouquíssimos, filmes no Brasil contemporâneo que dá conta destas relações que marcam o país pós-Lula: esse crescimento econômico maluco que vem modificando a paisagem urbana e provocando algumas mudanças sociais bastante interessantes" (Zamberlan, 2013, 19).

Da mesma Revista Interlúdio, Heitor Augusto nos garante que " $O$ Som ao Redor é disparado o que consegue, em tempos recentes, apresentar uma precisão cinematográfica a ponto de nos faz sentir o gozo de presenciar o Belo. De quebra, radiografar sintomas do Brasil pós-Lula” (Augusto, 2013, П2).

Tal precisão cinematográfica não se detém, no entanto, no Brasil pós-Lula, mas vai mesmo às priscas eras feudais: 
0 espaço em que a ação do filme ocorre é uma rua recheada por prédios em Setúbal, subdivisão do bairro de Boa Viagem, em Recife. Tal lugar, descobriremos, tem uma organização do poder que, apesar das [sic] casca urbana, tem pontos análogos a um latifúndio. Voltando mais no tempo, assemelha-se ao engenho da sociedade escravocrata (casa grande, vassalos, jagunços). Se formos mais longe nas comparações, essa rua reproduz a hierarquia de uma sociedade pré-Revolução Francesa (Augusto, 2013, १7).

Entretanto, a celebração do filme como retrato do país não se manteve apenas entre nossos críticos. A. O. Scott (The New York Times) foi um dos primeiros a reconhecer que: "O âmbito da sua narrativa é estreito, mas suas ambições são enormes e alcança nada menos que o esclarecimento do estado peculiar da sociedade brasileira (e não apenas brasileira)"8 (Scott, 2012, 13). Com a tese de que o filme atinge o universal a partir do local, como Cesar Zamberlan também aponta em sua crítica ao citar Tarkovski, o crítico americano ressalta que "alguns dos fatos que ocorrem no interior dessas paredes poderiam ser capítulos de uma novela de banalidades domésticas em Singapura ou São Francisco ou Cidade do Cabo ou Dubai” (Scott, 2012, ף2).

Constatação semelhante é feita por Alexandre Caetano (Artigos sobre Cinema): "A história que se desenvolve em Recife poderia ser adaptada para qualquer outra grande cidade, sobretudo litorânea, onde se concentrou a colonização do país” (Caetano, A., 2013, П2).

Destoando da unanimidade crítica, o cineasta Eduardo Escorel (Revista Piauí) aponta alguns defeitos de direção, como o fato de a trama principal ser retardada por enredos paralelos pouco relevantes, como é o caso da relação entre João e Sofia, o que torna o filme longo e lento. É também a única crítica que não extrapola o cenário circunscrito pelo filme e que efetivamente aparece na tela, embora reconheça a qualidade da obra:

A tentativa de tratar com realismo moradores comuns - patrões, empregados e prestadores de serviço- de uma rua qualquer, próxima ao mar, em um bairro de classe média de uma grande cidade do

8 Tradução nossa do original inglês. 
Nordeste, além de ser prova de coragem, tem 0 valor de explicitar a violência do cotidiano, deixando implícita uma ameaça indefinida, prestes a eclodir, que paira sobre todos (Escorel, 2013, १13).

Portanto, no que tange ao primeiro aspecto, a crítica é unânime, com exceção de Escorel, na sobredeterminação do caráter brasileiro do filme, que se caracteriza pela defesa de uma tese tanto sociológica (a radiografia da violência atual) quanto histórica (sua ligação com a oligarquia latifundiária pré-moderna).

\section{A estética da mistura de gêneros}

Do ponto de vista estético, a crítica ressalta o recurso ao cinema de gênero para classificar os procedimentos sonoros que, de tão importantes, nomeiam o filme. O som é praticamente um personagem, tratado de maneira pouco usual ou menos naturalista ou realista que as cenas cotidianas. Os sons do extracampo são intencionalmente trabalhados para a construção da sensação de medo e aparecem amplificados.

Maria do Rosário Caetano (Brasil de Fato) sintetiza bem essa importância do som no filme: "Sonoridades urbanas que potencializam de forma arrebatadora este denso painel de estórias de pessoas apavoradas-atormentadas por medo potencial". Trata-se do recurso ao horror metafísico, que, como ressalta a crítica, não "tem nada a ver com filmes de terror explícito, alimentados por sustos brutais e jorros espetaculares de sangue" (Caetano, M. do R., 2013, П16).

Heitor Augusto (Revista Interlúdio) é bastante didático sobre esse aspecto: "Percebe-se uma clara predileção ao cinema de gênero, em especial o horror, com uma montagem que privilegia o todo, em detrimento do um, construindo um clima de tensão no espectador que reflete a cultura do medo" (Augusto, 2013, П10).

Consuelo Lins ( $O$ Globo) explica essa mistura de gêneros recorrendo a Hitchcock:

0 surpreendente é que o filme alie tal realismo a procedimentos clássicos do suspense no cinema, mantendo o espectador sob tensão do 
começo ao fim. Muitas situações são construídas como se algo de terrível fosse acontecer, sem que a ameaça se realize, na maior parte das vezes - e quase não nos damos conta porque somos sucessivamente capturados por novos riscos. É a estratégia do suspense do cinema de Hitchcock aplicada à realidade brasileira, à descrição social em forma de crítica (Lins, 2013, ఇ2).

Ricardo Calil (Folha de S. Paulo) faz uma constatação semelhante, embora mais rápida, ao apontar que o diretor tem o mérito de "jamais entediar o espectador, produzindo obra em que a reflexão sobre a realidade esteja sempre conectada a um clima de suspense permanente, de humor sutil, de tragédia inevitável” (Calil, 2013, \$9).

Roberto Guerra (Cineclick) também chama atenção para esse aspecto: "A vida desses personagens, suas atitudes e também apatias e tédios diante das próprias existências são os responsáveis pela dinâmica asfixiante deste filme, por que não dizer, de horror” (Guerra, 2013, १7).

Eduardo Escorel (Revista Piauí) também comenta o trabalho sonoro e sua intencionalidade na trama, embora seja o único a apontar o que considera uma deficiência do filme, que é o fato de tais procedimentos se arrastarem em demasia, antes que a última cena esclareça e justifique a instauração de tal clima de tensão:

\begin{abstract}
Desde a primeira sequência, os surdos e a percussão da música de abertura, sobre fotografias antigas, criam a expectativa de algo momentoso que está por acontecer. Essa impressão é confirmada, à medida que 0 som ao redor progride, por outros sinais premonitórios, plantados de maneira esparsa na trilha sonora e na imagem, que vão se acumulando ao longo da narrativa - a irritante serra elétrica, o não menos incômodo uivo dos cães etc. Mas é preciso transcorrer mais de duas horas para saber afinal do que se trata (Escorel, 2013, १9).
\end{abstract}

A constatação de que o filme utiliza recursos do cinema de horror, principalmente no tratamento sonoro, para causar um clima permanente de suspense não impede, no entanto, que o filme seja visto pelo realismo ou naturalismo da encenação. 
Cesar Zamberlan (Revista Interlúdio) é o mais explícito a esse respeito:

O Som ao Redor não se prende à necessidade de narrar [...] simplesmente registra, limpando todas as camadas que poderiam dar conta de uma encenação artificial, na qual o dispositivo acaba se tornando maior que o filme e, por isso, no seu revés apequenando o filme. Kleber consegue evitar todas essas armadilhas, criando cenas nas quais os elementos dramáticos servem à construção de um panorama maior que os próprios personagens: 0 coletivo. Não há no filme 0 personagem principal, o indivíduo carregado pela câmera, e do qual tudo é preciso ser dito (Zamberlan, 2013, १5-१6).

Pablo Villaça (Cinema em Cena) também registra o realismo, embora destaque uma mudança ao longo do filme: "Mendonça é corajoso ao fugir do realismo que adotara até então ao investir, no terceiro ato, em uma abordagem que beira a fantasia” (Villaça, 2013, П9).

Por fim, vale destacar que, para Scott (The New York Times), o filme é um "thriller sem trama" (2012, 凤8), o que reforça o argumento de Cesar Zamberlan (Revista Interlúdio), além da menção que outros críticos fazem ao tom de crônica do filme, menos preso, portanto, ao compromisso da narrativa. A única voz destoante continua a ser a do cineasta Eduardo Escorel (Revista Piauí):

Ao contrário do que foi escrito, não é um "thriller sem trama". Ainda que só comece a ser explicitada no terço final, a vingança planejada acaba dominando todo 0 enredo de 0 som ao redor. Dessa maneira, durante os cerca de $80^{\prime}$ iniciais, quase tudo que antecede a eclosão da trama principal, em especial a relação do casal de namorados, João (Gustavo Jahn) e Sofia (Irma Bown), que percorre o filme do início ao fim, acaba parecendo menos relevante. Desequilíbrio prejudicial ao ritmo e que torna 0 som ao redor, além de longo, lento (Escorel, 2013, ๆ8).

\section{A permanência do novo}

A estética modernista, que não convém abordar aqui, fundou o culto ao novo. Não apenas o culto, mas seu papel de juiz, de índice de verificação de valor. Opondo-se à ideia de imitação herdada dos clássicos e intensificando a busca romântica pela originalidade, pela autenticidade da obra, o moderno se fundamenta pela novidade, pelo rompimento, pelo nunca antes 
feito, ou nunca realizado desse modo. Octavio Paz (1984, p. 17) foi lapidar ao sintetizar a fórmula do moderno: "rompimento da tradição e tradição do rompimento".

De fato, tornou-se moeda corrente a tradição do rompimento, a busca incessante e até previsível pelo novo. De 30 anos para cá, no entanto, algumas correntes apontam um processo de superação dessa lógica, em que o retorno do passado passa a ser exercitado, ainda que de maneira nova. Também não convém abordarmos essa discussão aqui, mas vale registrar que, para Umberto Eco (1985), é justamente esta a definição do pós-moderno: retorno irônico, ou não inocente, ao passado. Para o que nos interessa aqui, basta registrar que esse retorno não se dá pela imitação ou repetição do passado, mas por sua recontextualização irônica. Não se busca romper com o passado, mas atualizá-lo, misturá-lo, dissolvê-lo. Poderíamos citar inúmeros processos de resgate, como o vintage, a moda retrô, o retorno dos vampiros e zumbis etc. Mas, de modo geral, basta retermos a ideia de inovação ou renovação.

No caso do nosso objeto - os textos críticos sobre o filme O Som ao Redor e seus pressupostos estéticos-, observamos como permanece a valorização do que a obra propõe como novo, mesmo que esse novo não seja exatamente o mesmo de antes, mas venha expresso pela ideia de mistura de gêneros, como ressaltamos no item anterior.

Para Luiz Zanin (O Estado de S. Paulo), o filme é "espantosamente novo no panorama do cinema brasileiro" (Zanin, 2013, |2). Para Cesar Zamberlan (Revista Interlúdio), "é um dos poucos, pouquíssimos, filmes no Brasil contemporâneo que dá conta dessas relações que marcam o país pós -Lula [...]" (Zamberlan, 2013). Heitor Augusto (Revista Interlúdio) confessa a "sensação de que estamos presenciando um capítulo paradigmático da filmografia brasileira" (Augusto, 2013, १11). A novidade estaria em "abandonar a tradição didática catequizante que historicamente ronda a produção brasileira e devotar-se ao cinema de gênero como manancial de possibilidades para falar sobre o presente, quebrar expectativas" (Augusto, 2013, П13). 
Consuelo Lins ( $O$ Globo) também se vale do "poucas vezes" para abordar a novidade do filme, que retrata "uma violência mais rara no cinema brasileiro" com "crueza, perspicácia e humor" (Lins, 2013, १1). Ricardo Calil (Folha de S. Paulo) também o trata como "uma experiência rara no cinema brasileiro recente" (Calil, 2013, ๆ11). Não é diferente para Paulo Camargo (Gazeta do Povo), que o reconhece como "um dos filmes brasileiros mais relevantes e pertinentes dos últimos anos” (Camargo, 2013, ๆ1).

No caso de Roberto Guerra (Cineclick), o fenômeno não é mérito apenas de Kleber Mendonça Filho, mas dos cineastas de Pernambuco, "Estado nordestino [que] faz hoje o melhor e mais inventivo cinema do país" (Guerra, 2013, १1).

\title{
Para Ignacio Navarro (El Antepenúltimo Mohicano), o filme registra
}

\begin{abstract}
[...] momentos de fascinante verossimilhança e às vezes originalidade, como o uso que a dona de casa faz de seus eletrodomésticos; ou a cena em que um jovem bêbado não se lembra de onde ocorria a festa da qual saiu para comprar cerveja, e pede aos guardas contratados pelos moradores do bairro que indiquem o caminho. São também momentos que permitem abandonar o drama e introduzir um tom de comédia que torna o filme mais leve. De fato, o engenho é praticamente constante, graças a um estilo de total liberdade criativa, que parece tanto se basear na improvisação como num controle mais estrito (Navarro, 2013, १3). .9
\end{abstract}

Pablo Villaça (Cinema em Cena), para ressaltar o lugar único de $O$ Som ao Redor, recorre à diversidade das produções cinematográficas brasileiras, dada suas dimensões continentais. Assim, há "comédias rasteiras e popularescas, exercícios de estilo, experimentações narrativas, dramas densos e recriações históricas. E há $O$ Som ao Redor, primeiro longa de ficção do crítico Kleber Mendonça Filho" (Villaça, 2013, ף2).

\section{Modos de ler e considerações finais}

Antes de passarmos às considerações finais sobre este exercício hermenêutico de investigação dos pressupostos estéticos da crítica cinematográfica

9 Tradução nossa do original espanhol. 
a respeito do filme $O$ Som ao Redor, queremos dialogar, ainda que brevemente, com Tzvetan Todorov (2003). Em seu texto Como ler? (2003, p. 317-332), o búlgaro radicado na França apresenta quatro modalidades de leitura de uma obra e, embora seu alvo seja os textos literários, sua reflexão não perde nada quando aplicada ao presente caso.

Segundo Todorov, há a projeção, pela qual o crítico busca retornar ao original do qual partiu o artista ao criar sua obra. Assim, "O autor contribuiu com uma primeira passagem, do original para a obra; cabe ao crítico nos fazer percorrer o caminho inverso, fechar o círculo, retornando ao original” (2003, p. 317-318).

Esse procedimento, como vimos, aparece no primeiro elemento de recorrência da crítica: o reconhecimento do retrato do país. De fato, os textos críticos foram muito além do que o filme mostra ao deslocarem metonimicamente o cotidiano de um bairro de Recife para a representação sintética de todo o país. Nesse sentido, a crônica do cotidiano se transformou numa tese sociológica ou histórica — há para todos os gostos- do Brasil contemporâneo, ou pós-Lula. É como se o cineasta partisse do original, o Brasil, transformando-o numa obra, o filme, e a crítica fizesse o caminho contrário ao partir da obra para chegar ao Brasil e fechar, assim, o círculo que Todorov aponta sobre esse procedimento de leitura.

Sobressai nesse procedimento o espelhamento que o filme pretensamente faria da sociedade brasileira. E o frenesi da crítica ao reconhecer o país espelhado no filme aponta para um pressuposto estético que remonta aos primórdios das produções culturais brasileiras, antes mesmo da existência do cinema, quando se imputava ao teatro e à literatura a função de representar ou retratar ou captar ou inventar a alma brasileira. Podemos pensar nos primeiros românticos, no final do século XIX, nos modernistas, em Glauber Rocha, no Cidade de Deus, de Fernando Meirelles. Os matizes são enormes, evidentemente, mas a ideia fixa não se altera: $o$ artista brasileiro deve retratar seu país em suas obras.

A segunda atitude descrita por Todorov é o comentário, pelo qual o crítico busca explicar a obra parafraseando-a e mantendo-se fiel aos seus 
elementos internos. Embora não tenhamos ressaltado esse aspecto na seleção dos trechos aqui transcritos, merece menção o fato de que absolutamente todas as críticas analisadas parafrasearam, ainda que ligeiramente, parte do enredo do filme, mesmo quando apontado como um filme sem trama. Tal atitude é esperada, senão aconselhável, já que a crítica se dirige prioritariamente a um público que ainda não viu o filme e espera minimamente uma descrição para saber do que se trata.

No entanto, além dessa função mais básica, o procedimento de comentar o filme expondo da maneira mais fiel possível os elementos que o compõem se constitui em recurso retórico já que a fidelidade do comentário contribui para a validação da interpretação, do sentido do filme, enfim, dos elementos que fazem parte do referente ou do original do qual o filme partiu. Assim, o comentário reforça a projeção, como se a paráfrase do filme servisse de prova e contraprova do que se afirmou projetivamente.

O terceiro nível de leitura é a poética. No caso do filme, trata-se do segundo elemento estético apontado em nossa análise: os procedimentos estilísticos do filme. $\mathrm{O}$ cinema de gênero, o recurso ao horror, a recorrência da potência sonora, sua exploração extracampo, em suma, os procedimentos técnicos e formais que constituem o filme são considerados não apenas quanto ao filme como produto singular, mas ao cinema de modo geral, que, como toda arte, tem sua poética própria.

Finalmente, o quarto procedimento é batizado por Todorov como leitura e explicitado da seguinte forma:

0 objeto da leitura é o texto singular; seu objetivo, desmontar seu sistema. A leitura consiste em relacionar cada elemento do texto com todos os outros, estando estes repertoriados não em sua significação geral, mas com vistas a esse uso. Teoricamente, é fácil notar que ela se aproxima do impossível. Com a ajuda da linguagem, pretende apreender a obra como pura diferença, embora a própria linguagem se baseie na similitude, e nomeia o genérico, não o individual. A expressão "sistema do texto" é um oximoro. Só é possível na medida em que a diferença (a especificidade, a singularidade) não for pura. 0 trabalho de leitura consiste sempre, em maior ou menor grau, não 
em obliterar a diferença, mas em desmontá-la, em apresentá-la como um efeito de diferença cujo funcionamento pode ser conhecido. Sem jamais "atingir" o texto, a leitura poderá dele se aproximar infinitamente (Todorov, 2003, p. 321).

Assim, o trabalho de leitura, para Todorov, consiste em desmontar o texto e analisar a relação de seus elementos, tanto entre si quanto com relação a outras obras. Trata-se, obviamente, de um procedimento estruturalista, mas que contribuiria para situar a obra de maneira mais elástica ao considerar tanto sua singularidade, que jamais pode ser radical, quanto sua pertença a um todo maior, que, em última instância, conclui que "todos os textos podem ser considerados partes de um único texto que vem sendo escrito desde que o tempo existe" (Todorov, 2003, p. 329).

No entanto, o mais interessante das proposições de Todorov é que nenhum procedimento pode dar conta da obra já que se trata da leitura de um sistema simbólico por intermédio de outro. Por isso que a "metáfora do itinerário" é importante para Todorov, pois o diálogo entre o "aquém” do texto com o seu "além” justifica a própria leitura (Todorov, 2003, p. 332).

Em sentido mais amplo, podemos dizer que a constatação recorrente da crítica analisada de que $O$ Som ao Redor inscreve-se sob o signo da novidade parte justamente desse procedimento de comparação entre o que o filme apresenta de diferente no conjunto de seus elementos constitutivos com o que há de diferença no conjunto das obras cinematográficas (vistas em sua perspectiva histórica ou mais circunscritas às produções contemporâneas). Daí advém a valorização do novo como elemento estético, seja numa chave de leitura modernista, de rompimento com a tradição, seja numa chave pós-moderna (ou de outra nomenclatura, mas que guarda a semelhança de se diferenciar do moderno), por meio do retorno irônico ao passado ou da mistura de elementos (no caso, de gêneros cinematográficos).

Vale mencionar, ainda que de passagem, a quantidade de filmes com os quais $O$ Som ao Redor foi comparado, sem que, entretanto, turvasse o reconhecimento de sua originalidade. De Glauber Rocha a Haneke, de Ozu a Argento, de Carpenter a Beto Brant... Essa, aliás, parece ser a principal 
diferença entre os textos críticos. Talvez o único elemento que nos lembre de que os textos não são versões de um só texto, mas expressam também uma singularidade: a do leitor diante da obra.

Dessa forma, à guisa de conclusão, podemos sintetizar, levando em consideração o horizonte hermenêutico de Paul Ricoeur e os modos de leitura de Tzvetan Todorov, que os pressupostos estéticos que orientam o olhar dos textos críticos, especificamente no caso de $O$ Som ao Redor, resumem-se a três: 1) o filme apresenta uma crítica histórico-sociológica sobre as relações de classe no Brasil; 2) o filme utiliza recursos de gênero, como os provenientes do cinema de horror, para compor o clima de medo e a paranoia que perpassa as situações encenadas, e 3 ) o caráter inovador do filme, que reitera tanto a tradição moderna de busca do novo quanto valoriza o procedimento mais recente de reapropriação de linguagens consolidadas em contextos ainda não explorados, por meio da mistura de recursos estilísticos de gêneros diferentes.

A análise hermenêutica empreendida por este artigo concentrou-se na recepção crítica do filme $O$ Som ao Redor, por considerar que sua quase unanimidade, aliada a um entusiasmo pouco frequente, sinaliza de maneira mais límpida determinados pressupostos estéticos que orientariam os modos de leitura das obras cinematográficas contemporâneas visto que todo excesso beira à caricatura, e a caricatura auxilia o olhar no reconhecimento dos traços mais marcantes de um rosto ou cenário. Nada, absolutamente nada nos autoriza, no entanto, a extrapolar as conclusões a que chegamos no caso da crítica devotada a $O$ Som ao Redor, principalmente de seus três pressupostos estéticos recorrentes, para todo o cenário crítico brasileiro. É bem provável, não obstante, que tais elementos, considerados em conjunto ou isoladamente, compareçam em outros agrupamentos críticos sobre outras obras, assim como também é razoável prever o surgimento de elementos estéticos não relacionados aqui. Mas, para isso, serão necessárias novas pesquisas de cunho hermenêutico sobre a recepção crítica de obras cinematográficas contemporâneas, as quais registramos aqui como sugestão. 


\section{Referências}

Augusto, H. (2013). O Som ao Redor (2012), de Kleber Mendonça Filho. Revista Interlúdio, 4 jan. 2013 [acesso em 12 abril 2013]. Disponível em: <http://www.revistainterludio.com.br/?p=5139>

Aumont, J. e Marie, M. (2003). Dicionário teórico e crítico de cinema. Campinas, SP: Papirus.

Caetano, A. (2013). O Som ao Redor. Artigos sobre Filmes, 8 jan. 2013 [acesso em 16 abril 2013]. Disponível em: <http://www.artigosdecinema.blogspot.com.br/2013/01/o-som-ao-redor.html>

Caetano, M. do R. (2013). O Som ao Redor. Brasil de Fato, 22 jan. 2013 [acesso em 12 abril 2013]. Disponível em: <http://www.brasildefato.com.br/node/11654>

Calil, R. (2013). Crítica: diretor conecta reflexão social a clima de suspense e humor sutil. Folha de S. Paulo, 1 jan. 2013 [acesso em 12 abril 2013]. Disponível em: <http://www1.folha.uol.com. br/ilustrada/1208461-critica-diretor-conecta-reflexao-sociala-clima-de-suspense-e-humor-sutil.shtml>

Camargo, P. (2013). Uma crônica hipnótica do Brasil contemporâneo. Gazeta do Povo, 10 jan. 2013 [acesso em 12 abril 2013]. Disponível em: <http://www.gazetadopovo.com.br/cadernog/conteudo. phtml tl =1 \&id=1334647\&tit=Uma-cronica-hipnotica-do-Brasil-contemporaneo>

Durand, G. (1997). As estruturas antropológicas do imaginário. São Paulo: Martins Fontes.

Eco, U. (1985). Pós-Escrito ao Nome da Rosa. Rio de Janeiro: Nova Fronteira.

Escorel, E. (2013). O Som ao Redor - Violência Latente. Revista Piauí, 29 jan. 2013 [acesso em 12 abril 2013]. Disponível em: <http://re- 
vistapiaui.estadao.com.br/questoes-cinematograficas/o-som-aoredor-violencia-latente/>

Ferreira-Santos, M. e Almeida, R de (2012). Aproximações ao imaginário: bússola de investigação poética. São Paulo: Képos.

Guerra, R. (2013). O Som ao Redor. Cineclick, 2 jan. 2013 [acesso em 12 abril 2013]. Disponível em: <http://www.cineclick.com.br/criticas/ficha/filme/o-som-ao-redor/id/3112>

Lins, C. (2013). Tensão social como ela é. O Globo, 3 jan. 2013 [acesso em 12 abril 2013]. Disponível em: <http://rioshow.oglobo.globo.com/cinema/eventos/criticas-profissionais/o-som-ao-redor-7589.aspx>

Navarro, I. (2013). El Temor a lo Desconocido. El antepenúltimo mohicano, 13 abril 2013 [acesso em 16 abril 2013]. Disponível em: <http:// www.elantepenultimomohicano.com/2013/04/sonidos-de-barrio-critica.html>

Paz, O. (1984). Os Filhos do Barro: do Romantismo à Vanguarda. Rio de Janeiro: Nova Fronteir.

Puls, M. (2013). Obra retrata fim do coronelismo no país. Folha de S. Paulo, 17 fev. 2013 [acesso em 16 abril 2013]. Disponível em: <http:// www1.folha.uol.com.br/ilustrissima/1231438-obra-retrata-fimdo-coronelismo-no-pais.shtml>

Ricoeur, P. (2008). Hermenêutica e Ideologias. Petrópolis, RJ: Vozes.

Sabadin, C. (2013). “O Som ao Redor”, de Kleber Mendonça, estreia nos cinemas. Revista de Cinema, 2 jan. 2013 [acesso em 12 abril 2013]. Disponível em: <http://revistadecinema.uol.com.br/index.php/2013/01/o-som-ao-redor-de-kleber-mendonca-estreianos-cinemas $/>$ 
Scott, A. O. (2012). The Leisure Class Bears Its Burden. The New York Times, 23 ago. [acesso em 12 abril 2013]. Disponível em: <http:// movies.nytimes.com/2012/08/24/movies/neighboring-soundsdirected-by-kleber-mendonca-filho.html?_r=0>

Todorov, T. (2003). Poética da Prosa. São Paulo: Martins Fontes.

Villaça, P. (2013). Crítica. Cinema em Cena, 30 jan. 2013 [acesso em 12 abril 2013]. Disponível em: <http://www.cinemaemcena.com.br/Critica/Filme/5862/o-som-ao-redor >

Zamberlan, C. (2013). O Som ao Redor (2012), de Kleber Mendonça Filho. Revista Interlúdio, 4 jan. 2013 [acesso em 12 abril 2013]. Disponível em: <http://www.revistainterludio.com.br/?p=5124>

Zanin, L. (2013). Um som perturbador. O Estado de S. Paulo, 4 jan. 2013 [acesso em 12 abril 2013]. Disponível em: <http://blogs.estadao. com.br/luiz-zanin/um-som-perturbador $>$ 